\title{
A study on half-shaped printed monopole antenna with short stub for UWB system
}

\author{
Shunta Ichikawa ${ }^{\text {a) }}$ and Nobuyasu Takemura \\ Graduate School of Electronics, Information and Media Engineering, \\ Nippon Institute of Technology, \\ 4-1 Gakuendai, Miyashiro-mati, Minamisaitama-gun, Saitama 345-8501, Japan \\ a)2188003@sstu.nit.ac.jp
}

Abstract: In this paper, the authors propose a small printed monopole antenna corresponding to the frequency band of UWB (Ultra-wideband) system that use a frequency of $3.1 \mathrm{GHz}$ to $10.6 \mathrm{GHz}$. This antenna has a structure in which a bell-shaped UWB monopole antenna formed on a dielectric substrate (FR-4) has a half shape and a short stub is attached to the antenna. The size of the antenna is $30 \times 12 \times 1.6 \mathrm{~mm}^{3}$. The antenna is designed to be smaller than the conventional one proposed by the author, and can operate in the frequency band of the UWB system. From the simulation result, it is shown that good characteristics can be obtained to UWB application for high speed wireless communication.

Keywords: UWB, small antenna, short stub, impedance matching Classification: Antennas and Propagation

\section{References}

[1] M. Z. Win, D. Dardari, A. F. Molisch, W. Wiesbeck, and J. Zhang, "History and applications of UWB," Proc. IEEE, vol. 97, no. 2, pp. 198-204, Feb. 2009. DOI:10.1109/JPROC.2008.2008762

[2] FCC, "1st Report and Order on Ultra-Wideband Technology," Feb. 2002.

[3] R. Pyndiah, "An overview of UWB technology," IET Workshop on Practical Applications for Wireless Technology, pp. 65-80, 2006.

[4] A. M. Abbosh, "Miniaturization of planar ultrawideband antenna via corrugation," IEEE Antennas Wireless Propag. Lett., vol. 7, pp. 685-688, Nov. 2008. DOI:10.1109/LAWP.2008.2009323

[5] R. Azim, M. T. Islam, and N. Misran, "Compact tapered-shape slot antenna for UWB applications," IEEE Antennas Wireless Propag. Lett., vol. 10, pp. 1190-1193, Oct. 2011. DOI:10.1109/LAWP.2011.2172181

[6] N. Takemura and S. Ichikawa, "Experimental study of bell-shaped monopole antenna with short stub for UWB applications," International Symposium on Antennas and Propagation, Dec. 2017.

[7] I. Pele, A. Chousseaud, and S. Toutain, "Simultaneous modeling of impedance and radiation pattern antenna for UWB pulse modulation," IEEE AP-S 
International Symp., vol. 2, pp. 1871-1874, June 2004. DOI:10.1109/APS. 2004.1330566

\section{Introduction}

The Ultra Wideband (UWB) system is widely studied as a system that enables high-speed wireless communication by performing communication using a wide frequency band [1]. In 2002, The Federal Communication Commission (FCC) has approved the spectrum within the frequency $3.1 \mathrm{GHz}$ to $10.6 \mathrm{GHz}$ for ultra-wideband systems, and the design of an antenna covering those frequency band is required [2]. The antenna is required to have a small size, and it is desirable that the antenna have non-directional radiation characteristics assuming communication with devices in various directions [3]. Impedance matching technology used to improve antenna characteristics has been reported as a miniaturization technology for ultra-wideband antennas [4, 5]. A bell-shaped planar monopole antenna attached with a short stub has been proposed [6]. This antenna improves the impedance matching in the lower band by attaching a short stub and is an antenna with a wide band characteristic that satisfies the band of the ultra-wideband system. The size is $28 \times 20 \times 1.6 \mathrm{~mm}^{3}$. In this paper, we focus on the symmetrical structure of the previously proposed ultra-wideband antenna, and propose a half-shaped UWB monopole antenna with the antenna cut in half. By adjusting the parameters of the short stub and the ground conductor, the characteristics satisfying the frequency band of the ultra-wideband system are shown. In order to achieve impedance matching, the antenna is shaped by cutting off the microstrip line, and short stubs is useful for impedance matching in the low frequency band of the ultra-wideband system.

\section{Antenna design}

Fig. 1 shows the half-shaped printed monopole antenna with short stub for the UWB system. This antenna is formed on a dielectric substrate (FR-4: $\varepsilon_{\mathrm{r}}=4.4$, $\tan \delta=0.02$ ) with a length $\mathrm{L}=30 \mathrm{~mm}$, a width $\mathrm{W}=13 \mathrm{~mm}$, and a thickness $\mathrm{t}=1.6 \mathrm{~mm}$. The antenna is fed by microstrip transmission line to the monopole on a dielectric substrate, and the short stub is connected to the ground plane of the microstrip transmission line from the central lower part of the monopole through holes. The monopole and the ground conductor are half-shaped compared to the previously proposed antenna. The characteristic impedance is $50 \Omega$. In general, the equivalent circuit of the UWB monopole antenna can be considered as a series of multiple resonant circuits [7]. The short stub operates as a parallel impedance to the UWB monopole antenna, and the antenna's input impedance can be matched by properly adjusting the short stub's parallel impedance. This antenna structure provides broadband operation. The dimensions of the proposed antenna are length $(\mathrm{L})=30.0 \mathrm{~mm}$, width $(\mathrm{W})=13.0 \mathrm{~mm}$, length of microstrip line $\left(\mathrm{L}_{\mathrm{L}}\right)=10.0 \mathrm{~mm}$, width of microstrip line $\left(\mathrm{W}_{\mathrm{L}}\right)=2.0 \mathrm{~mm}$, width of antenna $\left(\mathrm{W}_{\mathrm{A}}\right)=12.0 \mathrm{~mm}$, length of ground $\left(\mathrm{L}_{\mathrm{G}}\right)=10.5 \mathrm{~mm}$, width of ground $\left(\mathrm{W}_{\mathrm{G}}\right)=12.0 \mathrm{~mm}$, length of short stub 


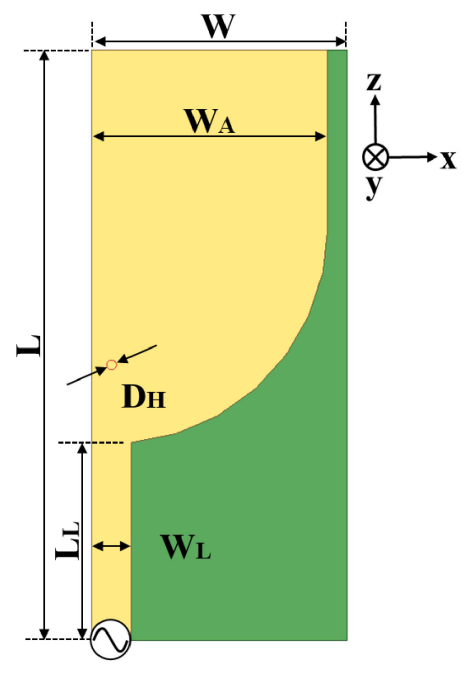

(a) front-view

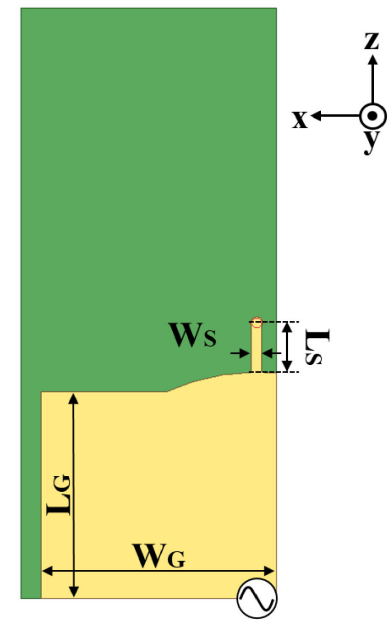

(b) back-view

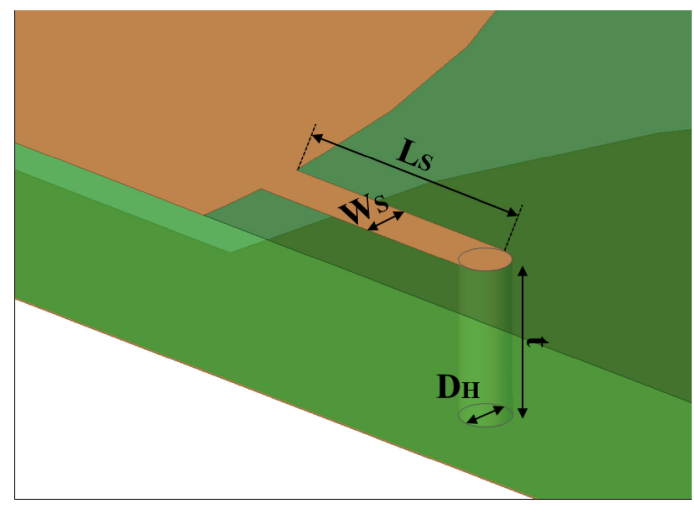

(c) Enlarged view of the short stub structure

Fig. 1. Antenna configuration

$\left(\mathrm{L}_{\mathrm{S}}\right)=2.5 \mathrm{~mm}$, width of short stub $\left(\mathrm{W}_{\mathrm{S}}\right)=0.5 \mathrm{~mm}$, and diameter of through hole $\left(D_{\mathrm{H}}\right)=0.5 \mathrm{~mm}$.

\section{Simulation results}

The antenna is analyzed using the electromagnetic field simulator Keysight EMPro. The antenna parameters are calculated using the same values as the reference values shown in chapter 1. Fig. 2 shows the calculation results of the characteristics of the antenna. In this figure, (a) shows the smith chart when the length of short stub is changed from $1.5 \mathrm{~mm}$ to $3.0 \mathrm{~mm}$ at $0.5 \mathrm{~mm}$ intervals, (b) shows the result when the width of short stub is changed from $0.3 \mathrm{~mm}$ to $0.9 \mathrm{~mm}$ at $0.2 \mathrm{~mm}$ intervals. And, (c) and (d) show comparison of s-parameters with short stub and without short stub in VSWR and smith chart. Calculation results with short stubs are indicated by blue solid lines, and calculation results without short stubs are indicated by red dotted lines. From Fig. 2(a), it is obtained that when the length of the short stub is increased, the capacitance component of the input impedance tends to increase. From Fig. 2(b), it is obtained that when the width of the short stub is increased, the inductance component of the input impedance tends to increased. The input impedance can be adjusted by changing the length of short stub $\left(\mathrm{L}_{\mathrm{S}}\right)$ and the width 


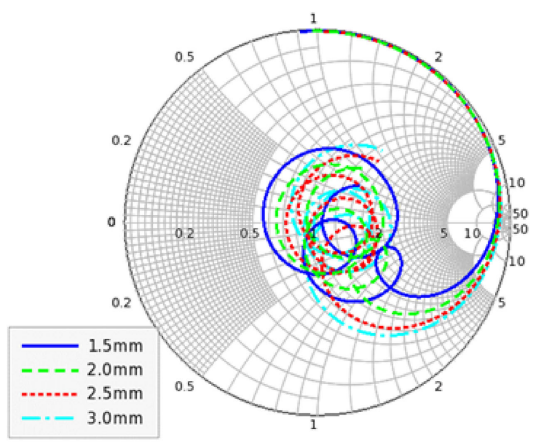

(a) Input impedance ( $L_{S}$ is changed)

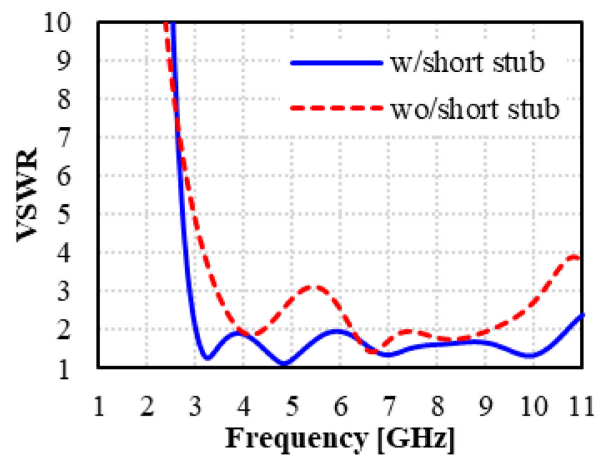

(c) VSWR

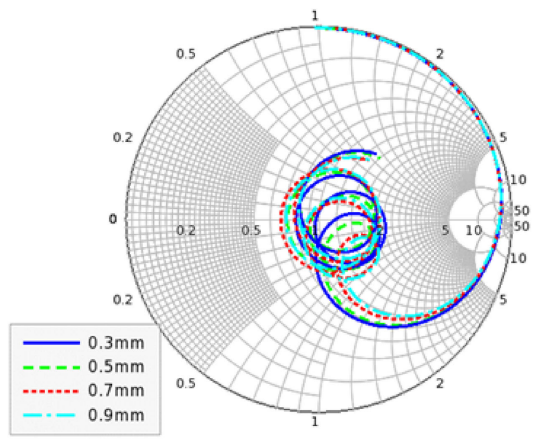

(b) Input impedance ( $\mathrm{W}_{\mathrm{S}}$ is changed)

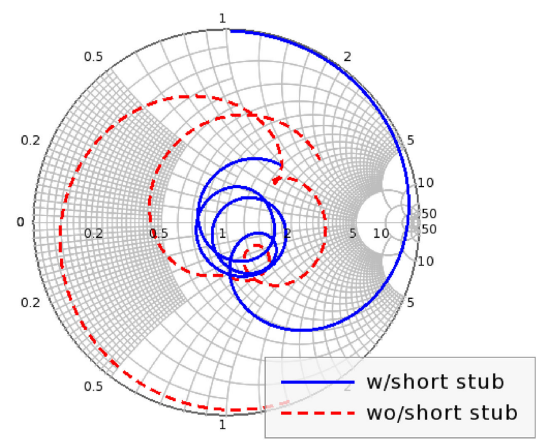

(d) Input impedance

Fig. 2. Simulation result of proposed antenna

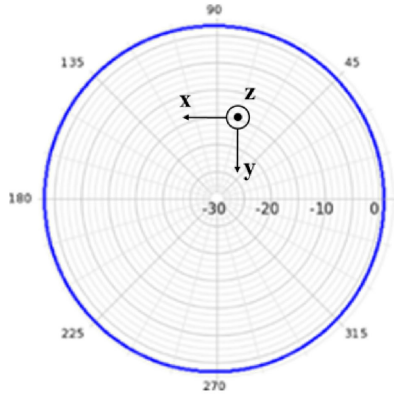

(a) $3.5 \mathrm{GHz}$

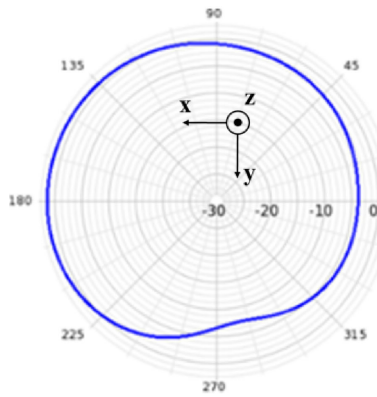

(d) $8.0 \mathrm{GHz}$

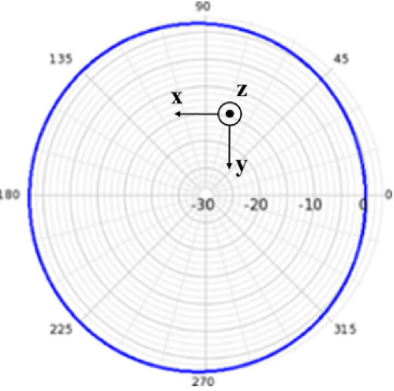

(b) $5.0 \mathrm{GHz}$

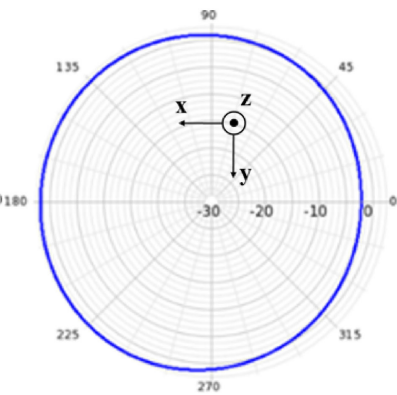

(c) $6.5 \mathrm{GHz}$

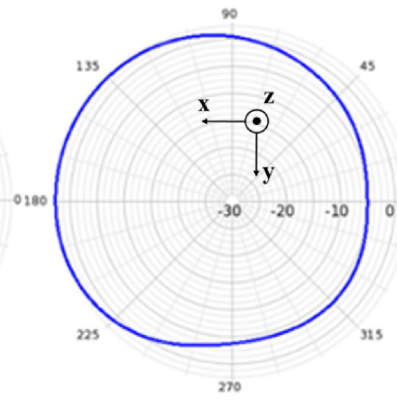

(e) $9.0 \mathrm{GHz}$

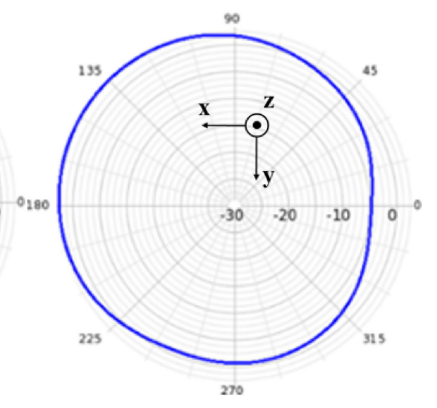

(f) $10.0 \mathrm{GHz}$

Fig. 3. Radiation pattern (x-y plane)

of short stub $\left(\mathrm{W}_{\mathrm{S}}\right)$. It can be solved the problem that when the antenna is designed small, the frequency band shifts to a high frequency and impedance matching in the low frequency is degraded. The proposed antenna's short stub is adjusted to

\section{() IEICE 2020}

DOI: 10.1587/comex.2019SPL0013 Received January 8, 2020 Accepted January 28, 2020

Publicized March 19, 2020

Copyedited June 1, 2020 
$\mathrm{L}_{\mathrm{S}}=2.5 \mathrm{~mm}$ and $\mathrm{W}_{\mathrm{S}}=0.5 \mathrm{~mm}$ for impedance matching. From the calculation results of VSWR, the proposed antenna showed good results that is the VSWR is 2 or less over the entire desired band of the ultra-wideband system. This result shows that even in the case of the half shape, almost the same characteristics as the conventional antenna could be obtained. The simulation result of radiation pattern is shown in Fig. 3. The radiation pattern in the $x-y$ plane is shown. The calculation frequencies are $3.5 \mathrm{GHz}, 5.0 \mathrm{GHz}, 6.5 \mathrm{GHz}, 8.0 \mathrm{GHz}, 9.0 \mathrm{GHz}$ and $10.0 \mathrm{GHz}$. From the calculation results, radiation in the cut direction at high frequencies is slightly degraded, however it can be confirmed that almost non-directional radiation patterns are obtained at each frequency. It can be confirmed that good results were obtained as an antenna for UWB high speed wireless communication applications.

\section{Conclusion}

A half-shaped printed monopole antenna corresponding to the desired frequency band of the UWB system is proposed, and the calculation results of the antenna characteristics are presented. By adjusting the length and width of the short stub, the input impedance of the antenna can be obtained a good value throughout the UWB system, and even if the antenna is designed to be small, a wideband characteristic that satisfies the desired frequency band of the UWB system is realized. It was also confirmed that nearly all of the omnidirectional radiation characteristics were obtained. The proposed antenna achives miniturization with an antenna configuration that is $30 \%$ size reduction of the conventional antenna, and achieves wideband characteristics that operate in the UWB frequency band.

\section{Acknowledgments}

This research was partially supported by grant from the Telecommunications Advancement Foundation (TAF). 